\title{
Environmental Impact Optimization of Reinforced Concrete Slab Frame Bridges
}

\author{
Majid Solat Yavari ${ }^{1,2}$, Guangli Du ${ }^{3}$, Costin Pacoste ${ }^{1,2}$ and Raid Karoumi ${ }^{1}$ \\ 1. KTH Royal Institute of Technology, Division of Structural Engineering and Bridges, 10044 Stockholm, Sweden; \\ 2. ELU Konsult AB, 10251 Stockholm, Sweden; \\ 3. The Faculty of Engineering and Science, Danish Building Research Institute, Aalborg University Copenhagen, 2450, Denmark
}

\begin{abstract}
The main objective of this research is to integrate environmental impact optimization in the structural design of reinforced concrete slab frame bridges in order to determine the most environment-friendly design. The case study bridge used in this work was also investigated in a previous paper focusing on the optimization of the investment cost, while the present study focuses on environmental impact optimization and comparing the results of both these studies. Optimization technique based on the pattern search method was implemented. Moreover, a comprehensive LCA (life cycle assessment) methodology of ReCiPe and two monetary weighting systems were used to convert environmental impacts into monetary costs. The analysis showed that both monetary weighting systems led to the same results. Furthermore, optimization based on environmental impact generated models with thinner construction elements yet of a higher concrete class, while cost optimization by considering extra constructability factors provided thicker sections and easier to construct. This dissimilarity in the results highlights the importance of combining environmental impact (and its associated environmental cost) and investment cost to find more material-efficient, economical, sustainable and time-effective bridge solutions.
\end{abstract}

Key words: LCA, slab frame bridge, environmental impact, structural optimization, pattern search.

\section{Introduction}

Today's construction sector is an essential contributor to economic development, but is also responsible for the consumption of a large amount of energy and raw materials. In 2015, the construction sector in Sweden represented 10\% of GDP (gross domestic product) and involved 311,000 people at an investment level of 388 billion Swedish Krona [1]. The construction of bridges, a fundamental type of infrastructure, plays an important role in this highly active industry. Accordingly, the reduction of the environmental impacts of bridges is important and should be taken into consideration in order to achieve a sustainable and environmentally friendly design [2].

In recent decades, researchers have applied several optimization algorithms in order to determine the

Corresponding author: Majid Solat Yavari, technologie licentiat; research fields: structural optimization, structural design, and LCA. E-mail: majidsy@kth.se. optimal design of different structures. Most of these methods concern the cost of the structure, in which reducing cost is the main objective, while environmental performance and other associated costs are rarely integrated into the optimization process. For instance, in a previous study performed by Yavari, Pacoste and Karoumi [3], cost-optimized designs of slab frame bridges were compared, showing the potential to reduce the cost of investment. This methodology was successfully applied for the automated and cost-optimal design of a new slab frame bridge, one of which has since been constructed [4]. However, the criteria of sustainable design and environmental performance should also be taken into account during decision-making in addition to technical feasibility, durability and cost. The use of multidimensional criteria may lead to controversy: the most environmentally friendly solution may not be the cheapest or the most efficient one with regard to the 
construction process. These conflicts should be considered early on in the design phase [2].

LCA (life cycle assessment) is a comprehensive, standardized and internationally recognized approach for quantifying all emissions, resource consumption and related environmental and health impacts linked to a service or product during its entire life cycle. It has the potential to provide a reliable environmental profile of structures; thus, it can be used in structural optimization design to assist decision-makers in selecting the most environmentally friendly solution. However, most LCA analyses are performed on existing designs at a stage in which it is too late to make any improvements [5, 6]. Therefore, this paper attempts to integrate LCA with a design optimization approach in the early planning phase in order to effectively incorporate multiple criteria, including environmental impacts and associated cost. Accordingly, in this paper, structural optimization is performed for concrete slab frame bridges by considering the environmental impacts of different designs and their associated costs.

LCA has seldom been used in the study of bridges [7]. Most previous studies have considered either a single indicator or only a few structural components. For example, Widman [8], Itoh and Kitagawa [9], Itoh et al. [10], Martin [11], Collings [12], Bouhaya et al. [13] and Habert et al. [14, 15] focused on energy consumption and $\mathrm{CO}_{2}$ emissions; meanwhile, Martin [11], Keoleian et al. [16] and Bouhaya et al. [13] confined the scope of their analysis to the bridge deck. According to the extensive literature review of Pieragostini et al. [17] on optimization performed with LCA methodology, most previous studies considered a single environmental impact in the objective function. Some examples of studies that mainly consider embedded energy or $\mathrm{CO}_{2}$ emissions are as follows: Camp and Assadollahi [18] in the optimization of reinforced concrete footings; Yepes et al. [19] in the optimization of reinforced concrete retaining walls; Cho et. al [20] in the optimization of high rise steel structures; Yeo and Gabbai [21] and Yeo and Potr [22] in the optimization of reinforced concrete frame structures; Ji, Hong and Park [23], in the decision-making process of nine structural building designs; and Paya-Zaforteza et al. [24] in the minimization of $\mathrm{CO}_{2}$ emissions of reinforced concrete building frames.

In addition to global warming, environmental sustainability also encompasses other indicators related to human health and the depletion of natural resources. Therefore, the environmental impact analyses focusing exclusively on global warming potential will not provide a full profile of potential environmental impacts [25]. Consequently, this research uses the ReCiPe method (described in the following) to cover not only global warming but also other important indicators regarding human health and the deterioration of natural resources. The current study is the first, to the best of the authors' knowledge, to evaluate the structural optimization of slab frame bridges considering all important environmental impact indicators. Regarding optimization of similar structures to slab frame bridges, Perea et al. [26] have presented cost optimization of 2D reinforced concrete box frames used in road constructions. In another work, Lombardero, Vidosa and Yepes [27] have studied optimization of reinforced concrete vaults used in road construction and hydraulic artificial tunnels.

Furthermore, involving the environmental cost into the total project cost has attracted increasing research interests. For instance, Park et al. [28] presented an optimization method to minimize the associated cost of $\mathrm{CO}_{2}$ emissions given the use of composite steel reinforced columns in high-rise buildings. In their study, $\mathrm{CO}_{2}$ emissions were transformed to cost using the unit carbon price; this cost was then added to the cost of materials and labor, in order to achieve a more sustainable design. In another study, Medeiros and Kripka [29] compared the environmental optimization of rectangular reinforced concrete columns based on several parameters (global warming potential, $\mathrm{CO}_{2}$ 
emission and energy consumption) with the cost optimization based on different optimization methods. Additionally, by using simulated annealing method Paya et al. [30] have performed multi-objective optimization of reinforced concrete building frames considering cost, constructability, and environmental impacts.

In the previous study of Yavari, Pacoste and Karoumi [4], a complete automated design and structural optimization considering investment cost was performed on realistic $3 \mathrm{D}$ model of concrete slab frame bridges. The obtained results showed the efficiency of the applied algorithms in the cost optimization of slab frame bridges. This methodology was applied during the design process of a concrete slab frame bridge to achieve a time-effective and cost-optimal design. In the current study, the optimization of environmental impacts is considered for the same bridge in order to compare the most economical and the most environment-friendly designs. For this purpose, the same assumptions (e.g., input variables, constraints, stopping criteria, etc.) were adopted and the only difference was in the objective function. The results of this comparison will contribute to establishing a combined methodology that considers both investment cost and environmental impacts in the design process, allowing for a more sustainable design of slab frame bridges.

\section{Method}

\subsection{Optimization Process}

In the abovementioned study of Yavari, Pacoste and Karoumi [4], a code with several modules was developed to produce parametric models of slab frame bridges. In the current study, the same code was used to study the environmental impacts of slab frame bridges. The automated design and iterative optimization process are presented in Fig. 1. The modeling and application of all relevant loads were performed in Module 1. Module 2 included structural analysis in 3D in the commercial finite element program, Abaqus Ver. 6.12 , as well as the extraction of section forces and load combinations. In a separate developed program, the necessary reinforcement to satisfy requirements of ULS (ultimate limit state), SLS (serviceability limit

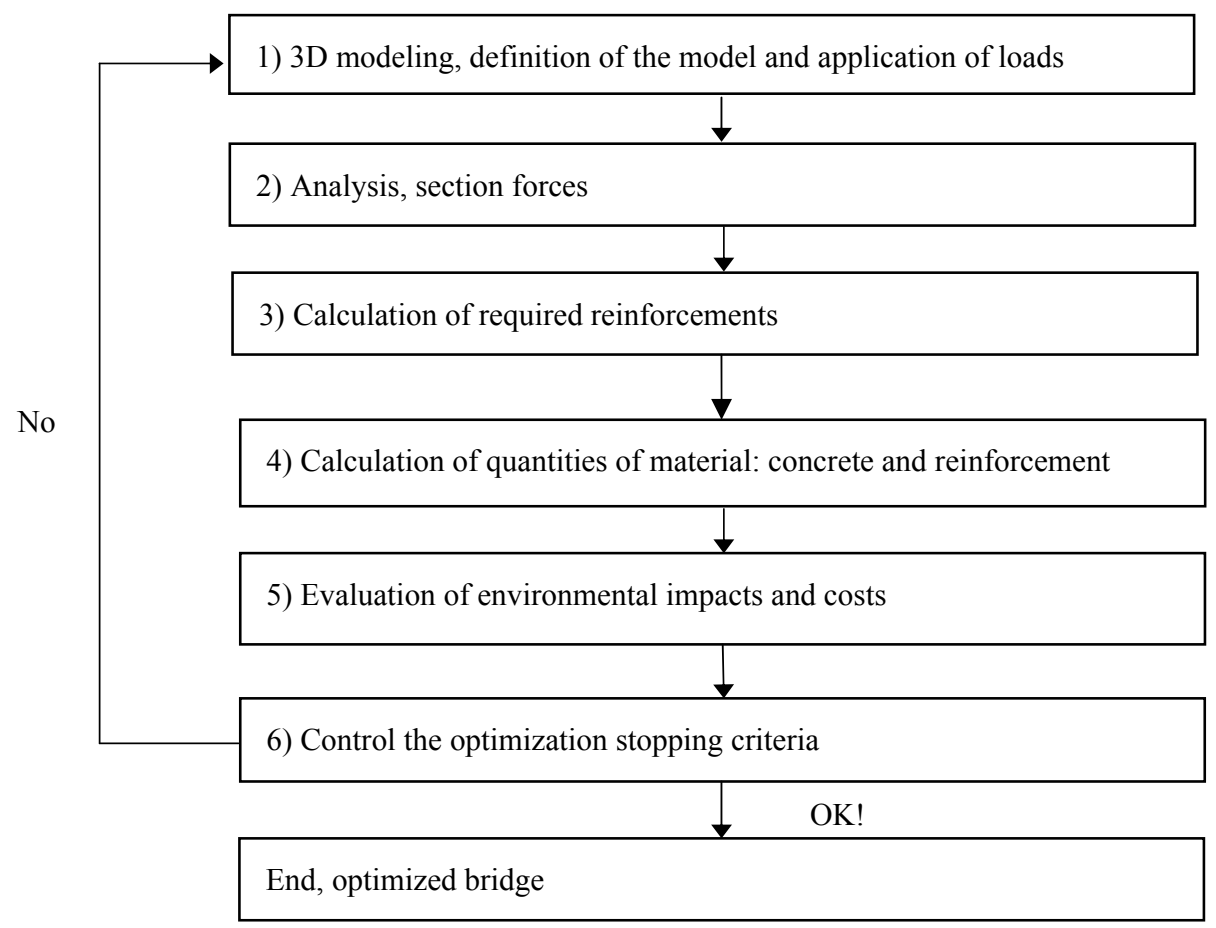

Fig. 1 The automated design and optimization process of a slab frame bridge [4]. 
state), fatigue checks and other design and constructability requirements for the whole bridge (constraints) were calculated as part of Module 3. In the following modules, the quantities of concrete and reinforcements, as well as the total environmental impacts of the bridge and its associated cost (objective function) were performed based on the ReCiPe method and the two monetary weighting systems. This process was performed by an optimization algorithm until the stopping criteria was fulfilled.

The results of the previous study showed that the PS (pattern search) method was more effective than the GA (genetic algorithm) in the cost optimization of the case study bridge. Therefore, the same algorithm and stopping criteria were also implemented in this study in order to utilize the same assumptions and render the results comparable. The PS method is a robust and efficient method that can perform well in optimization models that contain discontinuous, stochastic or random data types. This method is useful for problems not easily solved by mathematical or gradient-based algorithms. The MATLAB optimization toolbox was used for the optimization [31]. At each iteration, the pattern search method generates a set of points (variables), creating a "mesh", by adding the current point to some vectors, which is called the pattern. The pattern search method examines this set of points, searching for one with a lower objective function value ("polling"). If the algorithm finds a point in the new mesh with a lower objective function value, this point becomes the current point for the next step; otherwise, the algorithm generates and examines a new set of points around the current point. This process continues until the stopping criterion is met. Stopping criteria in optimization define the point at which the calculation can be stopped, terminating the process of finding the optimum value. It is important to select proper stopping criteria for each optimization problem. However, it should be considered that in practical engineering, it is often more important to have solutions that improve the initial design as desired rather than finding the lowest objective function value. In other words, in practical problems, we often desire to find a solution that is "good-enough" in a specific time domain rather than finding the global optimum [32]. In the following case study, the function tolerance of less than 0.05 (alteration in the resulting value of the objective function in two successive iterations) or a total calculation time of 10 hours (as a practical time limit) was considered as stopping criteria by the PS method (according to whichever criterion was met earlier). More information about the applied optimization algorithm has been presented in the previously published study of Yavari, Pacoste and Karoumi [4].

\subsection{ReCiPe Method}

Among the various existing LCA methodologies for interpreting environmental impacts [33], this paper considers the most comprehensive LCA methodology of ReCiPe midpoint (H) [34], which is the combined method of Eco-indicator 99 and CML 2002 including state-of-the-art impact categories [35]. The LCA modeling covers more than 1,000 substances within each material, from which the characterized impacts of CED (cumulative energy demand) and 11 types of mid-point impact categories are selected, namely GWP (global warming), ODP (ozone depletion), HTP (human toxicity), POFP (photochemical oxidant formation), PMFP (particulate matter formation), TAP (terrestrial acidification), FEP (freshwater eutrophication), MEP (marine eutrophication), TETP (terrestrial ecotoxicity), FETP (freshwater ecotoxicity) and METP (marine ecotoxicity). The comprehensive involvement of impact indicators remedies the absence of full spectrum of environmental indicators in the current state-of-the-art [7]. The study attempts to cover the environmental indicators as comprehensive as possible, however, this is not applicable due to limited availability of monetary values in practice. Therefore, in the objective function of optimization, only indicators available in both weighting methods are further considered and presented in Tables 1 and 2 . 
Furthermore, a cradle-to-grave "market" analysis was considered in the LCA (i.e., including the extraction, procurement, transportation of raw materials to the building site and waste of the product in trade and transport). Table 1 presents the environmental impacts of reinforcement and different concrete types evaluated in this study based on the ReCiPe midpoint method (H) V1.12. Long-term emissions are omitted and emissions due to infrastructure process are included. These impacts were calculated with data from the Ecoinvent version 3 database in the commercial LCA software SimaPro 8.2.0.

\subsection{Monetary Evaluation of Environmental Impacts}

The LCA modeling covered parameters of human health, ecosystem quality and resources, which are not straightforward to assess at the decision-making level without in-depth analyses. In order to aggregate the environmental impacts for an intuitively comparable set, these were weighted in order to convert the impacts into monetary values with common units. Ahlroth et al. [36] discussed the feasibility of evaluating the economic value of environmental impacts in a whole-life perspective. They proposed that one way to include external environmental costs in LCC (life-cycle costing) is to use monetary-weighted results obtained from environmental system analysis (such as LCA). There are several examples of such applications available in the literature. For instance, in the studies of Carlsson [37], Nakamura and Kondo [38], Kicherer et al. [39], Lim et al. [40] and Hunkeler et al. [41]. In this study, two monetary weighting systems, ecovalue08 with updated ecovalue12 weightings [36, 42, 43] and ecotax02 [44] were adopted and compared. The ecovalue monetary weighting set has been developed for evaluating mid-point environmental impacts based on willingness to pay, with a particular focus on Swedish conditions, while the ecotax set is based on environmental taxes and fees levied by the focal society [7]. Table 2 presents these two weighting sets.

\subsection{Optimization Problem}

In this study, the input variables consist of the dimensions of the bridge components and three concrete types. Concrete type, thickness of the slab in mid span (Tf1), thickness of the slab beside the haunches (Tf2), thickness of the frame legs beside foundations ( $\operatorname{Tr} 1)$, width of the haunches $(B f 1)$, height

Table 1 Characterized environmental impacts.

\begin{tabular}{|c|c|c|c|c|c|}
\hline Impact category* & Unit & $\begin{array}{l}\text { Concrete } \mathrm{C} 32 / 40 \\
\left(\mathrm{~m}^{3}\right)\end{array}$ & $\begin{array}{l}\text { Concrete } \\
\text { C35/45 (m })\end{array}$ & $\begin{array}{l}\text { Concrete C50/60 } \\
\left(\mathrm{m}^{3}\right)\end{array}$ & $\begin{array}{l}\text { Reinforcement. } \\
\text { (ton) }\end{array}$ \\
\hline Global warming(GWP) & $\mathrm{kg} \cdot \mathrm{CO}_{2} \cdot \mathrm{eq}$ & 344.505 & 352.694 & 383.748 & 2387.489 \\
\hline Human toxicity(HTP) & $\mathrm{kg} \cdot 1.4-\mathrm{DB} \cdot \mathrm{eq}$ & 20.381 & 20.835 & 21.968 & 417.752 \\
\hline Photochemical oxidantformation (POFP) & $\mathrm{kg} \cdot \mathrm{NMVOC}$ & 0.969 & 0.989 & 1.051 & 10.060 \\
\hline Terrestrial acidification (TAP) & $\mathrm{kg} \cdot \mathrm{SO}_{2} \cdot \mathrm{eq}$ & 0.918 & 0.934 & 0.998 & 9.428 \\
\hline Marine eutrophication (MEP) & $\mathrm{kg} \cdot \mathrm{N} \cdot \mathrm{eq}$ & 0.052 & 0.036 & 0.038 & 0.243 \\
\hline Marine ecotoxicity(METP) & $\mathrm{kg} \cdot 1.4-\mathrm{DB} \cdot \mathrm{eq}$ & 0.237 & 0.240 & 0.249 & 2.956 \\
\hline
\end{tabular}

*The $\mathrm{P}$ in each acronym refers to potential.

Table 2 Characterized environmental impact categories and monetary values.

\begin{tabular}{lllll}
\hline Environmental impact category & Acronym & Unit & Ecovalue (SEK) & Ecotax02 (SEK) \\
\hline Global warming & GWP & $\mathrm{kg} \cdot \mathrm{CO}_{2} \cdot \mathrm{eq}$ & 2.85 & 0.63 \\
Human toxicity & $\mathrm{HTP}$ & $\mathrm{kg} \cdot 1.4-\mathrm{DB} \cdot \mathrm{eq}$ & 2.81 & 1.5 \\
Photochemical oxidant formation & POFP & $\mathrm{kg} \cdot \mathrm{NMVOC}$ & 16 & 156 \\
Terrestrial acidification & $\mathrm{TAP}$ & $\mathrm{kg} \cdot \mathrm{SO}_{2} \cdot \mathrm{eq}$ & 30 & 15 \\
Marine eutrophication & $\mathrm{MEP}$ & $\mathrm{kg} \cdot \mathrm{N} \cdot \mathrm{eq}$ & 90 & 12 \\
Marine ecotoxicity & METP & $\mathrm{kg} \cdot 1.4-\mathrm{DB} \cdot \mathrm{eq}$ & 12 & 0.3 \\
\hline
\end{tabular}

* One Swedish Krona $(\mathrm{SEK}) \approx 0.11$ Euro $(€)$. 
of haunches (Hfl), thickness of frame legs beside haunches $(\operatorname{Tr} 2)$, thickness of wing walls beside frame legs (Tw1), and thickness of wing walls at the end (Tw2) were considered as independent input variables. Furthermore, instead of a detailed reinforcement pattern, the necessary reinforcement area in every mesh element of each part of the bridge was calculated in a separate program to fulfill the constraints; these were considered to be dependent variables. Using the required reinforcement amounts as the design variables for steel reinforcement instead of detailed reinforcement patterns, which is unnecessary especially in the first stages of the design process, will dramatically decrease the number of input variables and hence the algorithm convergence time. More information about this assumption has been stated in the previously published study of Yavari, Pacoste and Karoumi [4]. The bridge geometry was assumed to be symmetric, and the optimization was performed for the bridge deck, wing walls, and frame legs. Moreover, slipping, overturning, and soil capacity were taken into consideration. A 2D section of the bridge showing different variables and constant parameters is illustrated in Fig. 2.

\subsection{Constraints}

The constraints of the optimization model represent the design requirements according to the ULS (ultimate limit state), SLS (serviceability limit state), and fatigue control based on the established Eurocodes [45] and the Swedish annex for the design of bridges, TRVK Bro 11 [46]. The minimum necessary reinforcement, minimum spacing between steel bars, minimum and maximum thickness of each element and other constructability limitations based on the abovementioned standards were taken into account.

\subsection{Objective Function}

In this study, the associated environmental cost of concrete and the reinforcement of the bridge deck, frame legs, and wing walls were evaluated. Since the material for form working is usually rented and can be reused many times, the environmental impacts of form works are assumed to be negligible compared to the reinforcement and concrete and therefore excluded in the objective function. The objective function is presented in Eq. (1):

$$
\begin{gathered}
f(x)=\text { EnvCost }_{\text {concrete }}+\text { anchorage factor } \times \\
\text { EnvCost } t_{\text {reinforcement }} \\
\text { EnvCost }=\sum_{i=1}^{i=6} \text { impact }_{i} \times \text { monetary }_{i}
\end{gathered}
$$

where:

EnvCost $=$ total associated environmental cost of the six impact categories;

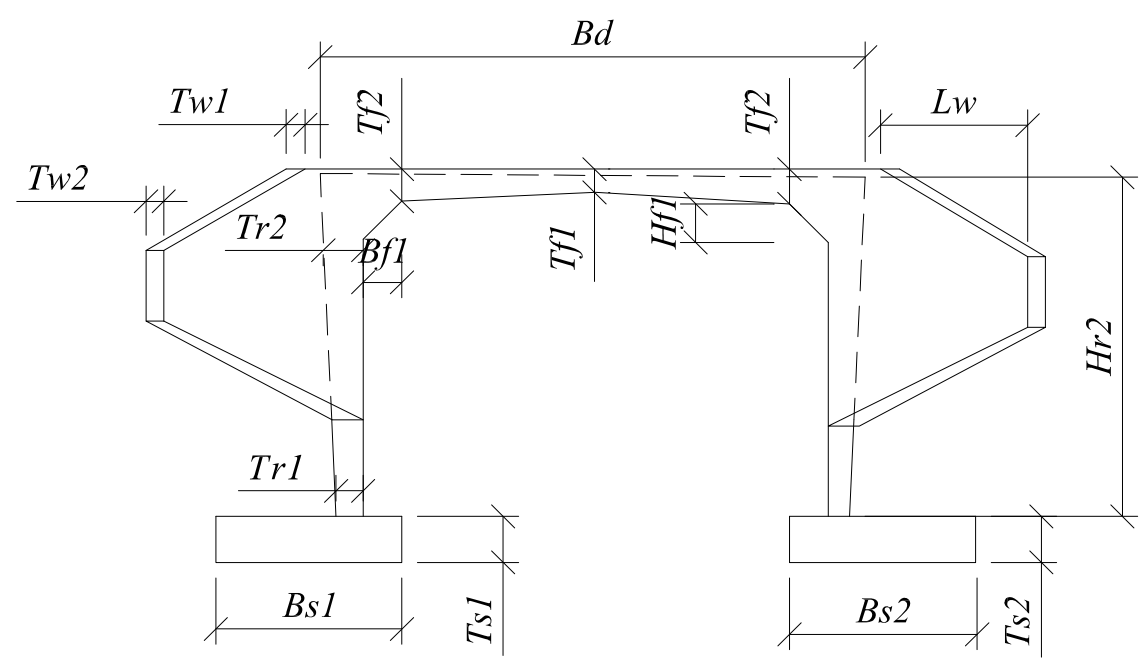

Fig. 2 Variables and constant parameters of a slab frame bridge [4]. 
impact $_{i}=$ impcat $_{i}$ based on the characterized environmental impact categories (Table 1);

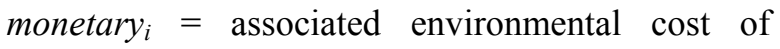
impact $_{i}$ based on the ecovalue or ecotax monetary weighting factors (Table 2);

anchorage factor $=1.4$, for the consideration of extra reinforcements due to design details and anchorage length based on practical experience in design.

Lesser thicknesses of certain sections would require denser and higher amounts of reinforcements with smaller spacing between bars, resulting in greater construction time and labor and a more expensive structure. Thus, the thickness of the different elements was considered as an indicator of constructability and factored into the price of reinforcement work in the cost optimization. For the LCA optimization, the thicknesses of the different sections do not have any remarkable extra effect (i.e., additional environmental costs of concrete and reinforcement due to the thinner sections) on total environmental impacts and thus constructability factors were not considered in this study.

\section{Results and Discussion}

\subsection{Case Study Application}

As previously mentioned, the complete design automation and cost optimization processes were applied to evaluate several scenarios before a bridge was constructed [4]. The same methodology has been used in the present study. In this section, the results of the environmental impacts optimization of the present study are compared with those of the prior cost optimization. The case study is the Sadjemjoki Bridge, a road bridge located on road Number 941 in Norrbotten County in Sweden. The Sadjemjoki Bridge is an open foundation slab frame bridge with no deck skewness. The free opening of the bridge is $6 \mathrm{~m}$; the total bridge length is $11.45 \mathrm{~m}$. The free width is $7 \mathrm{~m}$; the free height is $3.25 \mathrm{~m}$. The bridge is symmetrical in both transversal and longitudinal directions. Thus, the input variables are presented for one frame leg and wing wall, and these are the same for the other frame leg and wing walls. Fig. 3 shows the sketch of the bridge. Design parameters and the considered loads and their corresponding values for the structural design of the bridge are presented in Table 3.

Table 4 summarizes the results obtained for the optimum variables and associated environmental costs based on the two monetary weighting systems. The stopping criterion which was fulfilled more quickly was the function tolerance, with a total calculation time of 9 hours. The results of the previous investment cost optimization as well as corresponding investment costs for the ecovalue and ecotax solutions based on the unit costs of the previous study are also presented. As can be seen, the optimum values of the two monetary weighting systems are exactly the same; the environmentally optimized models resulted in lower associated environmental costs $(93,648$ SEK in ecovalue and 39,520 SEK in ecotax) in comparison with the corresponding associated environmental cost when investment cost is the objective function $(97,574$ SEK in ecovalue and 42,350 SEK in ecotax). However, environmentally optimized models lead to higher investment costs $(722,000 \mathrm{SEK})$ in comparison with the bridge that was previously found to be optimal solely based on investment cost (705,343 SEK). As previously mentioned, extra constructability factors due to thinner construction are not included in environmental optimization; consequently the environmentally optimized model indicated the use of concrete of a higher capacity to decrease the amount of concrete, thus leading to the use of thinner elements. Ultimately, the designers preferred an economical solution (in which investment cost was the objective function) due to considerations related to the constructability factors. The differences in the results of cost optimization and environmental optimization highlight the importance of integrating multiple criteria in structural designs. In future research, a methodology 


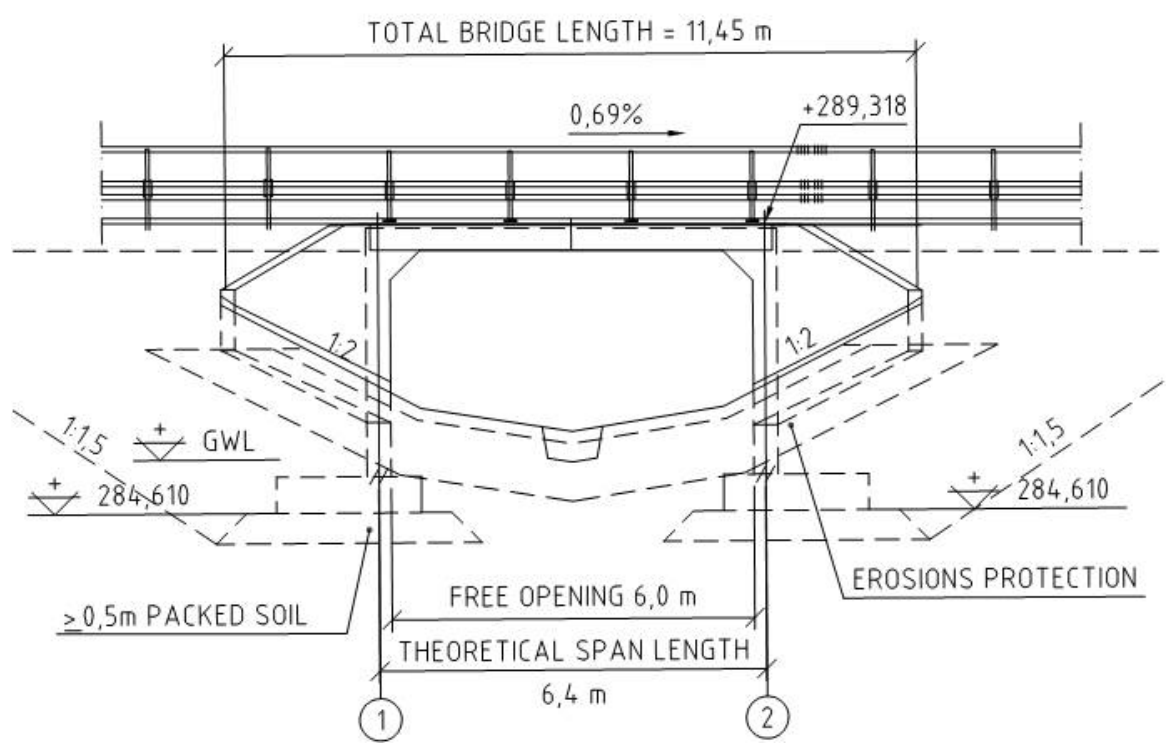

Fig. 3 Sketch of the Sadjemjoki Bridge [4].

Table 3 Design parameters and load assumptions [4].

\begin{tabular}{|c|c|}
\hline \multicolumn{2}{|l|}{ Design and load assumptions } \\
\hline Reinforcement type & B500B \\
\hline Foundation & $0.5 \mathrm{~m}$ packed soil, modeled as springs \\
\hline Safety class & 2 \\
\hline Life time & 80 years \\
\hline Exposure class & XD1/XF4 except upper side deck: XD3/XF4 \\
\hline Dead weight & $\gamma_{\text {concrete }}=25 \mathrm{kN} / \mathrm{m}^{3}$ \\
\hline Overburden & $\gamma_{\text {soil,dry }}=18 \mathrm{kN} / \mathrm{m}^{3}, \gamma_{\text {soil,wet }}=11 \mathrm{kN} / \mathrm{m}^{3}$ \\
\hline Average ground water level & $H_{w}=0.9 \mathrm{~m}$ above foundation lower side \\
\hline Surfacing & $Q_{\text {surfacing }}=1.75 \mathrm{kN} / \mathrm{m}^{2}$ \\
\hline Even increase in temperature & $\Delta T=31^{\circ}$, creep ratio $=0.28$ \\
\hline Even decrease in temperature & $\Delta T=-41^{\circ}$, creep ratio $=0.28$ \\
\hline Uneven increase in temperature & $T_{\max }=6.6^{\circ}, T_{\min }=-6.6^{\circ}$, creep ratio $=0.28$ \\
\hline Uneven decrease in temperature & $T_{\max }=4^{\circ}, T_{\min }=-4^{\circ}$, creep ratio $=0.28$ \\
\hline Shrinkage & Applied as decrease in temperature by $25^{\circ}$, creep ratio $=1.5$ \\
\hline Road traffic load & Load Models 1 and 2 and classification traffic vehicles \\
\hline Surcharge & $\mathrm{P}=20 \mathrm{kN} / \mathrm{m}^{2}, k_{0}=0.34$, rectangular constant distribution \\
\hline Earth pressure & $k_{0}=0.39, \gamma_{d r y}=18 \mathrm{kN} / \mathrm{m}^{3}, \gamma_{w e t}=11 \mathrm{kN} / \mathrm{m}^{3}$ \\
\hline Braking force & Total force $=255 \mathrm{kN}$, imposed on the whole deck \\
\hline Traffic lateral force & Total force $=64 \mathrm{kN}$, imposed on the whole deck \\
\hline Support yielding & Vertical and horizontal on each support, $0.01 \mathrm{~m}$ \\
\hline Guardrail load & Linear load magnitude on each edge beam: $0.5 \mathrm{kN} / \mathrm{m}$ \\
\hline Wind load on traffic & Traffic profile height $=2.6 \mathrm{~m}$, load pressure: $1.3 \mathrm{kN} / \mathrm{m}^{2}$ \\
\hline Wind load on structure & Imposed structure height $=1.8 \mathrm{~m}$, load pressure: $1.2 \mathrm{kN} / \mathrm{m}^{2}$ \\
\hline Resistant earth pressure & Applied on frame legs \\
\hline Fatigue load cycle & 50,000 ; Average daily traffic in a year: 5,000 \\
\hline
\end{tabular}


Table 4 Summary of the results.

\begin{tabular}{|c|c|c|c|c|c|c|c|c|c|c|c|c|}
\hline Objective function & $\begin{array}{l}T f 1 \\
(\mathrm{~m})\end{array}$ & $\begin{array}{l}T f 2 \\
(\mathrm{~m})\end{array}$ & $\begin{array}{l}\operatorname{Tr} 1 \\
(\mathrm{~m}) \\
\end{array}$ & $\begin{array}{l}\operatorname{Tr} 2 \\
(\mathrm{~m}) \\
\end{array}$ & $\begin{array}{l}H f 1 \\
(\mathrm{~m})\end{array}$ & $\begin{array}{l}B f 1 \\
(\mathrm{~m})\end{array}$ & $\begin{array}{l}\text { Tw1 } \\
\text { (m) }\end{array}$ & $\begin{array}{l}T w 2 \\
(\mathrm{~m})\end{array}$ & $\begin{array}{l}\text { Concrete } \\
\text { type }\end{array}$ & $\begin{array}{l}\text { Investment cost } \\
\text { (SEK) }\end{array}$ & $\begin{array}{l}\text { Ecov. } \\
\text { (SEK) }\end{array}$ & $\begin{array}{l}\text { Ecotax } \\
\text { (SEK) }\end{array}$ \\
\hline Ecovalue & 0.38 & 0.38 & 0.38 & 0.45 & 0.65 & 0.15 & 0.30 & 0.30 & $\mathrm{C} 50 / 60$ & 722,000 & 93,648 & 39,520 \\
\hline Ecotax & 0.38 & 0.38 & 0.38 & 0.45 & 0.65 & 0.15 & 0.30 & 0.30 & $\mathrm{C} 50 / 60$ & 722,000 & 93,648 & 39,520 \\
\hline Investment cost & 0.40 & 0.40 & 0.40 & 0.40 & 0.50 & 0.50 & 0.30 & 0.30 & $\mathrm{C} 35 / 45$ & 705,343 & 97,574 & 42,350 \\
\hline
\end{tabular}
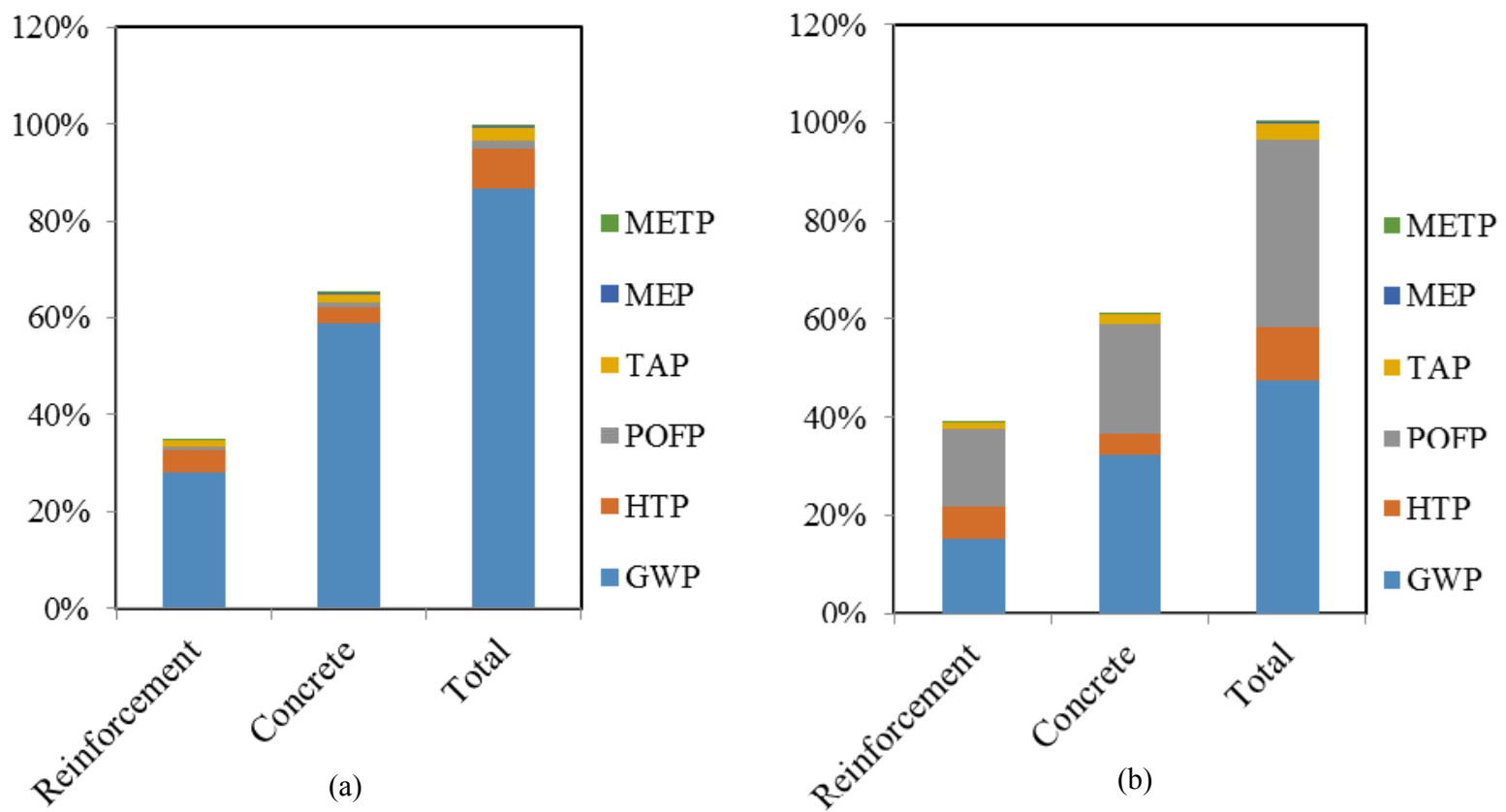

Fig. 4 Environmental impacts of the environmentally-optimized bridge based on: (a) ecovalue monetary system; (b) ecotax monetary system.

that would combine environmental impacts and investment cost is under investigation by the present authors. Both criteria should be considered to determine more sustainable, material-efficient, economical and time-effective bridge solutions.

Fig. 4 shows the associated environmental costs related to the environmental impacts of the environmentally-optimum bridge in different impact categories based on ecovalue and ecotax monetary systems. In both weighting systems, the concrete makes the greatest contribution toward environmental costs, rather than the reinforcement, representing $65 \%$ of the impact in ecovalue system and $61 \%$ in the ecotax system.

In both weighting systems, GWP gives the highest contribution toward the total associated environmental cost, up to $87 \%$ of the cost in ecovalue system and $47 \%$ of the cost in the ecotax system. HTP in the ecovalue represents the second highest contribution of nearly $8.3 \%$, while this value is $10.9 \%$ in the in ecotax system, representing the third highest contribution. In this latter system, the second highest contributor at $38.2 \%$ of the total impact is POFP, while this value is only $1.6 \%$ in the ecovalue system. The other three impact categories (TAP, MEP and METP) contribute less than $4 \%$ in both weighting systems.

\section{Conclusions}

In this study, the environmental impacts optimization of concrete slab frame bridges was performed using the ReCiPe method and two monetary weighting systems. The environmental optimization was compared to the cost optimization of the same case study performed in the previously published study of 
Yavari, Pacoste and Karoumi [4]. In summary, the following conclusions can be presented:

Structural optimization considering environmental impacts and their associated environmental costs was able to be efficiently implemented and applied in the design process of slab frame bridges.

Optimization based on the ecovalue and ecotax, two applied monetary weighting systems, led to the same results.

Optimization based on environmental impacts led to thinner concrete sections using a higher class of concrete; meanwhile, the cost optimization considered constructability factors and provided thicker sections and easier to construct design.

The designers preferred the economical solution due to the considered constructability factors; however, a multi-objective optimization that considers both environmental impacts and investment cost simultaneously is necessary in order to obtain more sustainable designs in the future.

Moreover, in future research, a sensitivity analysis should also be performed to examine the impact of the different variables on the results. An integrated optimization that would consider both investment and environmental costs for other bridge types such as beam bridges is also a part of the ongoing research of the present authors.

\section{Acknowledgments}

The authors wish to express their gratitude to the Swedish consulting company, ELU Konsult AB, and the Swedish Transportation Administration (Trafikverket), for the financial and technical support of this project; we also thank Nadia Al-Ayish for her contribution in extracting the LCA data.

\section{References}

[1] The Swedish Construction Federation (Sveriges Byggindustrier). 2015. "Fakta om Byggandet (Construction statistic 2015)." Accessed July 15, 2016. https://www.sverigesbyggindustrier.se/faktaostatistik. (in Swedish)

[2] Du, G. 2015. "Life Cycle Assessment of Bridges, Model
Development and Case Studies." Ph.D. thesis, Royal Institute of Technology, Stockholm, Sweden.

[3] Yavari, M. S., Pacoste, C., and Karoumi, R. 2014. "Structural Optimization of Slab Frame Bridges Using Heuristic Algorithms." Presented at International Conference on Engineering and Applied Science Optimization, Kos, Greece, 4-6 June 2014.

[4] Yavari, M. S., Pacoste, C., and Karoumi, R. 2016. "Structural Optimization of Concrete Slab Frame Bridges Considering Investment Cost." Journal of Civil Engineering and Architecture 10: 982-94.

[5] Du, G., and Karoumi, R. 2013. "Life Cycle Assessment of a Railway Bridge: Comparison of Two Superstructure Designs." Journal of Structure and Infrastructure Engineering 9 (11): 1149-60.

[6] Thiebault, V., Du, G., and Karoumi, R. 2013. "Design of Railway Bridges Considering Life-Cycle Assessment." In Proceedings of the Institution of Civil Engineers: Bridge Engineering 166 (4): 240-51.

[7] Du, G., Safi, M., Pettersson, L., and Karoumi, R. 2014. "Life Cycle Assessment as a Decision Support Tool for Bridge Procurement: Environmental Impact Comparison among Five Bridge Designs." The International Journal of Life Cycle Assessment 19 (12): 1948-64.

[8] Widman, J. 1998. "Environmental Impact Assessment of Steel Bridges.” J. Constr. Steel. Res. 46 (1): 291-3.

[9] Itoh, Y., and Kitagawa, T. 2003. "Using $\mathrm{CO}_{2}$ Emission Quantities in Bridge Life Cycle Analysis.” Engineering Structures 25: 565-77.

[10] Itoh, Y., et al. 2005. "Life Cycle Environmental Impact and Cost Analyses of Steel Bridge Piers with Seismic Risk." In Proceedings of the 9th International Conference on Structural Safety and Reliability, 273. Rome, Italy, 19-23 June 2005.

[11] Martin, A. J. 2004. "Concrete Bridges in Sustainable Development." In Proceedings of the Institute of Civil Engineers: Engineering Sustainability 157 (4): 219-30.

[12] Collings, D. 2006. "An Environmental Comparison of Bridge Form." Proceedings of the ICE Bridge Engineering 159 (4): 163-8.

[13] Bouhaya, L., Le Roy, R., and Feraille-Fresnet, A. 2009. "Simplified Environmental Study on Innovative Bridge Structure." Environ. Sci. Technol. 43 (6): 2066-71.

[14] Habert, G., Arribe, D., Dehove, T., Espinasse, L., and Le Roy, R. 2012. "Reducing Environmental Impact by Increasing the Strength of Concrete: Quantification of the Improvement to Concrete Bridges." Journal of Cleaner Production 35: 250-62.

[15] Habert, G., Denarié, E., Šajna, A., and Rossi, P. 2013. "Lowering the Global Warming Impact of Bridge Rehabilitations by Using Ultra High Performance Fibre Reinforced Concrete." Cement and Concrete Composites 
38: 1-11.

[16] Keoleian, G. A., Kendall, A., Dettling, J., et al. 2005. "Life Cycle Modeling of Concrete Bridge Design: Comparison of Engineered Cementitious Composite Link Slabs and Conventional Steel Expansion Joints." Journal of Infrastructure Systems 11 (1): 51-60.

[17] Pieragostini, C., Mussati, M. C., and Aguirre, P. 2012. "Review on Process Optimization Considering LCA Methodology." Journal of Environmental Management 96: 43-54.

[18] Camp, C. V., and Assadollahi, A. 2013. " $\mathrm{CO}_{2}$ and Cost Optimization of Reinforced Concrete Footings Using a Hybrid Big Bang-Big Crunch Algorithm." J. Struct Multidisc Optim. 48: 411-26.

[19] Yepes, V., Gonzalez-Vidosa, F., Alcala, J, and Villalba, P. 2012. " $\mathrm{CO}_{2}$-Optimization Design of Reinforced Concrete Retaining Walls Based on a VNS-Threshold Acceptance Strategy.” J. Comput. Civ. Eng. 26: 378-86.

[20] Cho, Y. S., Kim, J. H., Hong, S. U., and Kim, Y. 2012. "LCA Application in the Optimum Design of High Rise Steel Structures." Renewable and Sustainable Energy Reviews 16: 3146-53.

[21] Yeo, D. H., and Gabbai, R. D. 2011. "Sustainable Design of Reinforced Concrete Structures through Embodied Energy Optimization." J. Energy and Buildings 43: 2028-33.

[22] Yeo, D. H., and Potr, F. A. 2013. "Sustainable Design of Reinforced Concrete Structures through CO2 Emission Optimization.” J. Struct Eng. 41 (3): B4014002.

[23] Ji, C., Hong, T., and Park, H. S. 2014. "Comparative Analysis of Decision-Making Methods for Integrating Cost and $\mathrm{CO}_{2}$ Emission-Focus on Building Structural Design." Energy and Buildings 72: 186-94.

[24] Paya-Zaforteza, I., Yepes, V., Hospitaler, A., and González-Vidosa, F. 2009. " $\mathrm{CO}_{2}$-Optimization of Reinforced Concrete Frames by Simulated Annealing." J Engineering Structures 31: 1501-8.

[25] Laurent, A., Olsen, S. I., and Hauschild, M. Z. 2012. "Limitations of Carbon Footprint as Indicator of Environmental Sustainability." Journal of Environmental Science \& Technology 46 (7): 4100-8.

[26] Perea, C., Baitsch, M., Vidosa, F. G., and Hartmann, D. 2008. "Design of Reinforced Concrete Bridge Frames by Heuristic Optimization." J. Advances in Engineering Software 39: 676-88.

[27] Lombardero, A. C., Vidosa, F. G., and Yepes Piqueras, V. 2011. "Heuristic Optimization of Reinforced Concrete Road Vault Underpasses" Advances in Engineering Software 4 (42): 151-9.

[28] Park, H. S., Bongkeun, K., Yunah, S., Yousok, K., Taehoon, H., and Se, W. C. 2013. "Cost and $\mathrm{CO}_{2}$ Emission Optimization of Steel Reinforced Concrete Columns in
High-Rise buildings.” Energies 6: 5609-24.

[29] Medeiros, G. F., and Kripka, M. 2014. "Optimization of Reinforced Concrete Columns According to Different Environmental Impact Assessment Parameters." Engineering Structures 59: 185-94.

[30] Payá-Zaforteza, I., Yepes, V., González-Vidosa, F., Hospitaler, A. 2008. "Multiobjective Optimization of Reinforced Concrete Building Frames by Simulated Annealing." Computer-Aided Civil and Infrastructure Engineering 23 (8): 575-89.

[31] The MathWorks Inc. 2012. Global Optimization Toolbox User's Guide. Natick, MA 01760-2098.

[32] Bengtlars, A., and Väljamets, E. 2014. "Optimization of Pile Groups-A Practical Study Using Genetic Algorithm and Direct Search with Four Different Objective Functions." TRITA-BKN-Examensarbete. ISSN: 1103-4297; 409, 2014.

[33] Du, G., and Karoumi, R. 2014. "Life Cycle Assessment Framework for Railway Bridges: Literature Survey and Critical Issues." Journal of Structure and Infrastructure Engineering 10 (3): 277-94.

[34] Goedkoop, M. J., Heijungs, R., Huijbregts, M., De Schryver, A., Struijs, J., and Van Zelm, R. 2009. ReCiPe 2008, A life Cycle Impact Assessment Method Which Comprises Harmonised Category Indicators at the Midpoint and the Endpoint Level. First edition Report I: Characterisation for Ministry of VROM. The Hague, The Netherlands.

[35] European Commission, Joint Research Centre Institute for Environment and Sustainability. 2010. ILCD Handbook: General Guide for Life Cycle Assessment-Detailed Guidance. 21027, Ispra (VA), Italy.

[36] Ahlroth, S., Nilsson, M., Finnveden, G., Hjelm, O., and Hochschorner, E. 2011. "Weighting and Valuation in Selected Environmental Systems Analysis Tools-Suggestions for Further Developments." J Clean Prod. 19 (2): 145-56.

[37] Carlsson, R. M. 2005. "Economic Assessment of Municipal Waste Management Systems-Case Studies Using a Combination of Life Cycle Assessment (LCA) and Life Cycle Costing (LCC)." Journal of Cleaner Production 13: 253-63.

[38] Nakamura, S., and Kondo, Y. 2006. "Hybrid LCC of Appliances with Different Energy Efficiency." The International Journal of Life Cycle Assessment 5: 305-14.

[39] Kicherer, A., Schaltegger, S., Tschochohei, H., and Ferreira Pozo, B. 2007. "Eco-efficiency, Combining Life Cycle Assessment and Life Cycle Costs via Normalisation." The International Journal of Life Cycle Assessment 12 (7): 537-43.

[40] Lim, S. R., Park, D., and Park, J. M. 2007. “Environmental and Economic Feasibility Study of a Total Wastewater 
Treatment Network System.” Journal of Environmental Management 88: 564-75.

[41] Hunkeler, D., Lichtenvort, K., and Rebitzer, G. Lead authors: Ciroth A., Huppes G., Klöpffer W., Rudenauer I., Steen B., and Swarr T. (Editors). 2008. Environmental Life Cycle Costing. SETAC, Pensacola, FL (US) in collaboration with CRC Press, Boca Raton, FL, USA.

[42] Ahlroth, S., and Finnveden, G. 2011. "Ecovalue08-A New Valuation Set for Environmental Systems Analysis Tool." Journal of Cleaner Production 19 (17): 1994-2003.

[43] Finnveden, G., Håkansson, C., and Noring, M. 2013. "A New Set of Valuation Factors for LCA and LCC Based on Damage Costs: Ecovalue 2012." In Perspectives on
Managing Life Cycles: Proceedings of the 6th International Conference on Life Cycle Management, 197-200.

[44] Finnveden, G., Eldh, P., and Johansson, J. 2006. "Weighting in LCA Based on Ecotaxes-Development of a Mid-point Method and Experiences from Case Studies." The International Journal of Life Cycle Assessment 11: 81-8.

[45] European Committee for Standardization. 2002. European Standards (Eurocodes). Parts 1 to 9.

[46] The Swedish Transport Administration (Trafikverket). 2012. TRVK Bro 11: Technical Requirements for Bridges. publ. nr 2011:085, Sweden. 